http://jmscr.igmpublication.org/home/ ISSN (e)-2347-176x ISSN (p) 2455-0450 crossref DOI: https://dx.doi.org/10.18535/jmscr/v8i2.59

\title{
Detection of Metallo- $\beta$-lactamase producing gene (bla viM) among gram negative non-fermenting bacteria causing wound infection in patients attending a tertiary care hospital in Kolkata
}

\author{
Authors \\ Priyanka Chakrabarty ${ }^{1}$, Ushnish Chakrabarty ${ }^{2}$ \\ ${ }^{1}$ Department of Microbiology, Medical College \& Hospital, Kolkata \\ ${ }^{2}$ Department of CTVS, Medical College \& Hospital, Kolkata
}

\begin{abstract}
The introduction of Carbapenems into clinical practice represented a great advance for the treatment of serious bacterial infection caused by $\beta$ - lactam resistant bacteria. Carbapenem resistance has been observed more commonly in non-fermenters such as Pseudomonas and Acinetobacter species. The common form of resistance is through lack of drug penetration i.e. porin mutations and efflux pumps and for carbapenem -hydrolysing $\beta$-lactamases. Acquired MBL have recently emerged as one of the most worrisome resistance mechanisms owing to their capacity to hydrolyse all $\beta$-lactams including carbapenems. Hence, in this study we tried to find out the prevalence of metallo- $\beta$-lactamase producing gene (bla $\left.a_{V I M}\right)$ among non fermenting gram negative bacilli causing wound infections from the pus samples received in the Department of Microbiology; Medical College, Kolkata over a period of one year. We found the prevalence to be $7.36 \%$.
\end{abstract}

\section{Introduction}

Carbapenem resistance has been observed more commonly in nonfermenters such as Pseudomonas spp and Acinetobacter spp. The common form of resistance is through lack of drug penetration i.e. porin mutations and efflux pumps and for carbapenem -hydrolysing $\beta$-lactamases. Based on molecular studies two classes of carbapenem hydrolyzing enzyme have been described: serine enzymes possessing a serine moiety at the active site, and metallo- $\beta$-lactamase (Class B) requiring divalent cations as co-factors for enzyme activity. ${ }^{1}$ Metallo- $\beta$ - lactamase producing bacteria are popularly known as superbugs due to their increased development of drug resistance to carbapenems \& mainly cause healthcare associated infections. Screening and confirmation of metallo- $\beta$ - lactamase producing bacteria causing carbapenem resistance is not easily and routinely detected in microbiology laboratory as identification of the carbapenemase genes relies mostly on molecular techniques.

So this study has been designed to detect the MBL producing genes among the non fermenting bacteria which are frequently associated with wound infections among patients in a tertiary care hospital in Kolkata.

\section{Objectives}

To study the prevalence of metallo- $\beta$ - lactamase producing genes among non fermenting gram negative bacilli causing wound infections from the 
clinical samples (pus samples) received in the Department of Microbiology, Medical College, Kolkata over a period of one year.

\section{Specific Objectives of the Study}

1) To isolate and identify the most common carbapenem resistant non fermenting gram negative bacilli causing wound infection.

2) Phenotypic identification of the carbapenem resistant non fermenting gram negative bacilli.

3) Genotypic identification of the most common metallo- $\beta$ - lactamase producing non fermenting bacteria.

\section{Materials \& Methods \\ Study Setting and Timelines}

In this prospective, analytical, observational study; conducted between 1st January 2016 to $31^{\text {st }}$ December 2016, the pus samples from wound infections collected in the Department of Microbiology, Medical College and Hospital Kolkata; were processed. Isolation and identification of the microorganisms and their antimicrobial susceptibility as well as phenotypic detection of carbapenem resistant gram negative non fermenting bacteria were completed. Positive samples were taken for genotypic detection. Samples other than pus like blood, urine, body fluids etc., samples in which gram negative non fermenting bacteria were not isolated \& Carbapenem sensitive isolates were excluded.

\section{Sample Size}

Considering the fact that about 2000 pus samples are received annually by the Department of Microbiology, Medical College, Kolkata; a sample size statistically representative of the population should be about 323 (accepting a Confidence Level of $95 \%$ \& a Margin of Error of $5 \%$ ).

Therefore in this Study 350 pus samples from wound infections had been evaluated.

\section{Parameters Studied}

1. Isolation and identification of the non fermenting gram negative bacteria were done by standard microbiological procedure and antimicrobial susceptibility test were done by Kirby-Bauer disc diffusion method and were interpreted as per CLSI (Clinical \& Laboratory Standards Institute) guidelines ${ }^{2}$ (table- 1 ).

2. Those found to be carbapenem resistant Gram negative non-fermenters were further tested by automated system VITEK 2- compact) for antibiotic sensitivity testing, MIC determination, carbapenemase production and interpreted according to CLSI guidelines. ${ }^{2}$ Those Gram Negative Bacteria having MIC of $\geq 2 \mu \mathrm{g} / \mathrm{ml}$ for imipenem \& meropenem were further subjected to phenotypic tests for detection of carbapenemase.

\section{Phenotypic Test \\ IMP-EDTA Combined Disc Diffusion Method}

- An overnight culture suspension of the test isolate was adjusted to a turbidity $0.5 \mathrm{Mac}$ Farland standard \& was inoculated on the surface of a Mueller Hinton agar.

- A $10 \mu \mathrm{g}$ imipenem disc and IMP - EDTA $(10 / 750 \mu \mathrm{g})$ discs were placed on the agar.

- After a $24 \mathrm{hr}$ incubation of the plate, the result was read.

- A $5 \mathrm{~mm}$ increase in the inhibition zone around the IMP - EDTA disc as compared to the IMP disc was interpreted as positive. Result of the phenotypic tests were compared with that of the VITEK 2compact.

The positive samples were taken for genotypic analysis by Polymerase Chain Reaction (PCR) and agarose gel electrophoresis.

\section{Genotypic Test (Polymerase Chain Reaction):}

The samples which were positive for metallo- $\beta$ lactamase, detected by the IMP-EDTA COMBINED DISC DIFFUSION method were further tested by Conventional PCR for gene detection. 


\section{Extraction of DNA}

The samples were inoculated in LB (Luria Bertini) broth. After overnight culture, the broth was allowed to centrifuge (9000rpm) for 5 minutes at $4^{0} \mathrm{C}$. The pellets were collected. To this Tris EDTA buffer, detergent SDS (10\% Sodium Dodecyl Sulphate), lysis enzyme Proteinase K $(20 \mathrm{mg} / \mathrm{ml})$ were added $\&$ incubated for 1 hour.

To this Phenol-choloroform mixture (1:1) was added. Again centrifugation was done (12000rpm) for 10 minutes at $4{ }^{\circ} \mathrm{C}$. The supernatant was taken \& RNAase was added. To this again Phenolcholoroform mixture (1:1) was added \& it was centrifuged (12000rpm) for 10 minutes at $4^{0} \mathrm{C}$. The supernatant was taken \& Potassium acetate (2M Potassium acetate in 3M Acetic acid, pH-5.2) \& Isopropanol were added. Centrifugation was done again (10000rpm) for 10 minutes at $4^{0} \mathrm{C}$. The precipitate was then taken $\&$ dissolved in Tris EDTA (pH-7.2). About $3 \mu$ l of extracted DNA was taken $\&$ electrophoresis was done with $0.8 \%$ Agarose gel.

\section{Amplification of Extracted DNA}

A. Reaction: This was carried out in a special PCR machine called THERMOCYCLER. The extracted DNA was subjected to repeated cycles (30-35 numbers) of amplification, which took about 90-120 minutes. For amplification, at first temperature was raised to $95^{\circ} \mathrm{C}$ for enzyme activation. Each amplification cycle had 3 steps:-

1) Denaturation at $95^{\circ} \mathrm{C}$ - separation of dsDNA into 2 separate single strands.
2) Primer annealing at $\mathbf{5 5}^{\mathbf{0}} \mathbf{C}$ - Primer is a short oligonucleotide, complimentary to a small sequence of the target DNA. It was annealed to the complimentary site on the target ssDNA.

3) Extension of Primer at $\mathbf{7 2}^{\mathbf{0}} \mathbf{C}$ - This step was catalysed by Taq Polymerase enzyme, which kept on adding the free nucleotides to the growing end of the Primer. Final extension step was done at $72^{\circ} \mathrm{C}$ for 10 minutes.

\section{B. PCR Mastermix}

1) Reaction buffer $(5 \mu \mathrm{l}), \quad \operatorname{dNTP}(5 \mu \mathrm{l})$, Magnesium Chloride $(3 \mu \mathrm{l})$.

2) Primer:

VIM (Forward)-5'GTTTGGTCGCATATCGCAAC3'(1.25 $\mu$ I), VIM (Reverse)5'AATGCGCAGCACCAGGATAG3'(1. 25 $\mu \mathrm{l})$.
3) 2.5 units Taq Polymerase 4.
4) DNA template- $5 \mu 1$.
5) The total volume was made upto $50 \mu \mathrm{l}$ by adding Molecular Grade Highly Purified Water.

\section{Gel electrophoresis of amplified DNA}

The amplified DNA was electrophoretically migrated according to molecular size by performing agarose gel electrophoresis using $2 \%$ Agarose gel. If desired PCR product (230bp amplicon size) was present, then fluorescence with orange band was seen under UV transilluminator.

Table-1: Interpretation of antimicrobial susceptibility test by Kirby-Bauer disc diffusion method as per CLSI guidelines.

\begin{tabular}{|l|c|c|c|c|c|}
\hline \multicolumn{2}{|c|}{} & \multicolumn{3}{c|}{ Zone Size(in mm) } \\
\hline $\begin{array}{l}\text { Antimicr- } \\
\text { obial Agent }\end{array}$ & $\begin{array}{c}\text { Disc } \\
\text { Potency }\end{array}$ & Organism & Resistant & Intermediate & Susceptible \\
\hline & & Enterobacteriaceae & $\leq 19$ & $20-22$ & $\geq 23$ \\
& & P. aeruginosa & $\leq 15$ & $16-18$ & $\geq 19$ \\
Meropenem & $10 \mu \mathrm{g}$ & Acinetobacter spp. & $\leq 14$ & $15-17$ & $\geq 18$ \\
\hline & & Enterobacteriaceae & $\leq 19$ & $20-22$ & $\geq 23$ \\
& & P. aeruginosa & $\leq 15$ & $16-18$ & $\geq 19$ \\
Imipenem & $10 \mu \mathrm{g}$ & Acinetobacter spp. & $\leq 18$ & $19-21$ & $\geq 22$ \\
\hline
\end{tabular}




\section{Results and Analysis}

Out of the 350 pus samples collected from infected wounds, 218 came out to be Gram negative. The Gram positive samples were not processed any further. Of the 218 Gram negative bacteria, 95 were Non-fermenters. 61 Nonfermenters were Carbapenem resistant by Antimicrobial Susceptibility Test [AST] \& 42 among these Carbapenem resistant strains were MBL producers detected phenotypically. However 7 among these were blavIM gene positive by PCR. Our patients were aged between 5 and 86 years, with the maximum $(40.83 \%)$ number of Gram negative samples coming from patients aged between 21 to 40 years.

Samples were more from the male patients (male: female $=1.3: 1$ )

Majority of the samples were collected from General Surgery wards (74\%), followed by Orthopaedics wards (15\%). Remaining came from Gynae-obstrectrics, CTVS \& Onco- Surgery wards. Among all the wound, Burns accounted for $25.22 \%$ of all Gram negative sample sources. (chart-1).

Chart-1: Distribution of wounds from which pus samples were collected

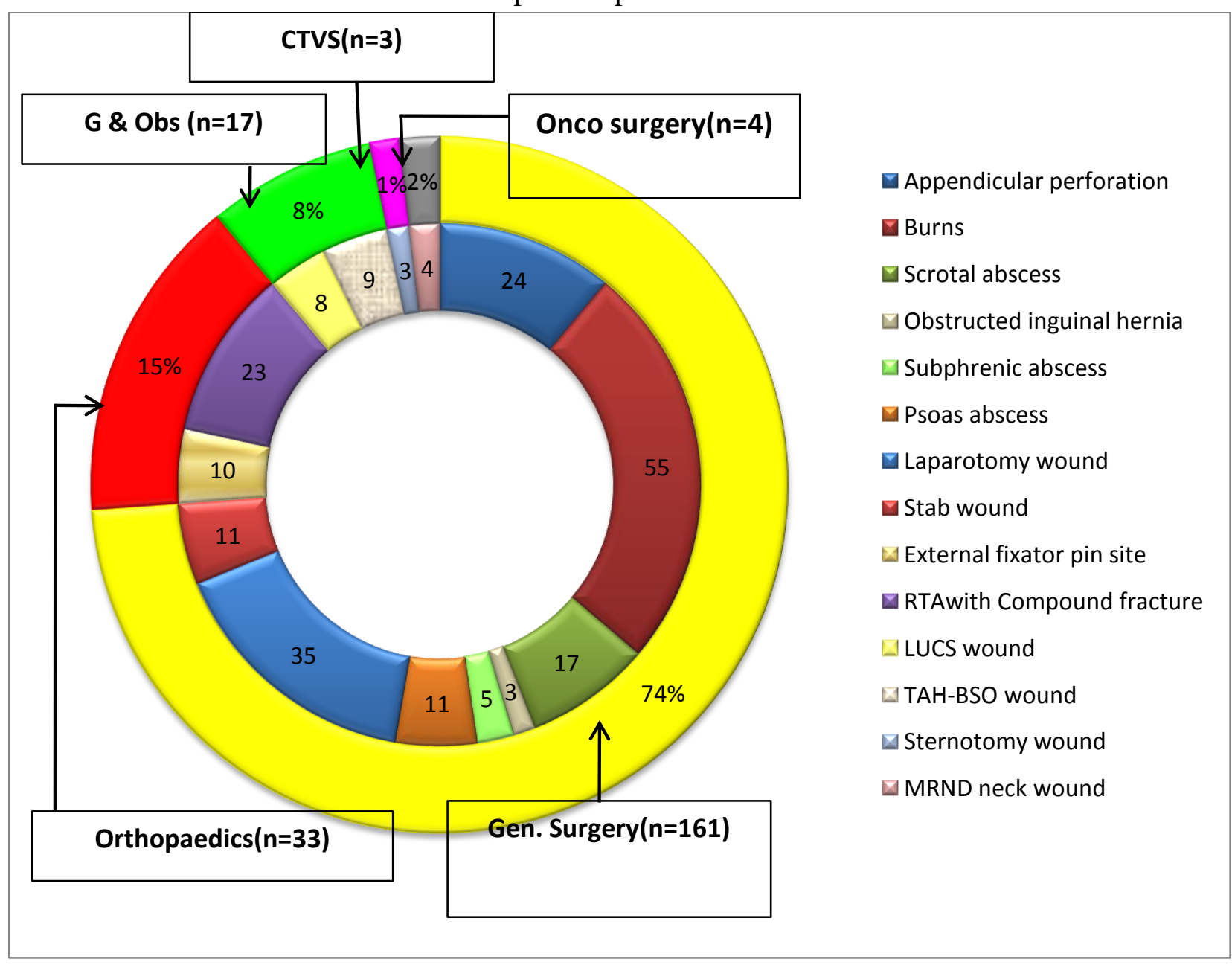

Klebsiella spp.(25.23\%) was the predominant Gram negative organism, closely followed by Pseudomonas aeruginosa $(24.31 \%)$.(chart-2) 


\section{JMSCR Vol||08||Issue||02||Page 326-333||February}

Chart-2: Gram negative organisms isolated from the pus samples.

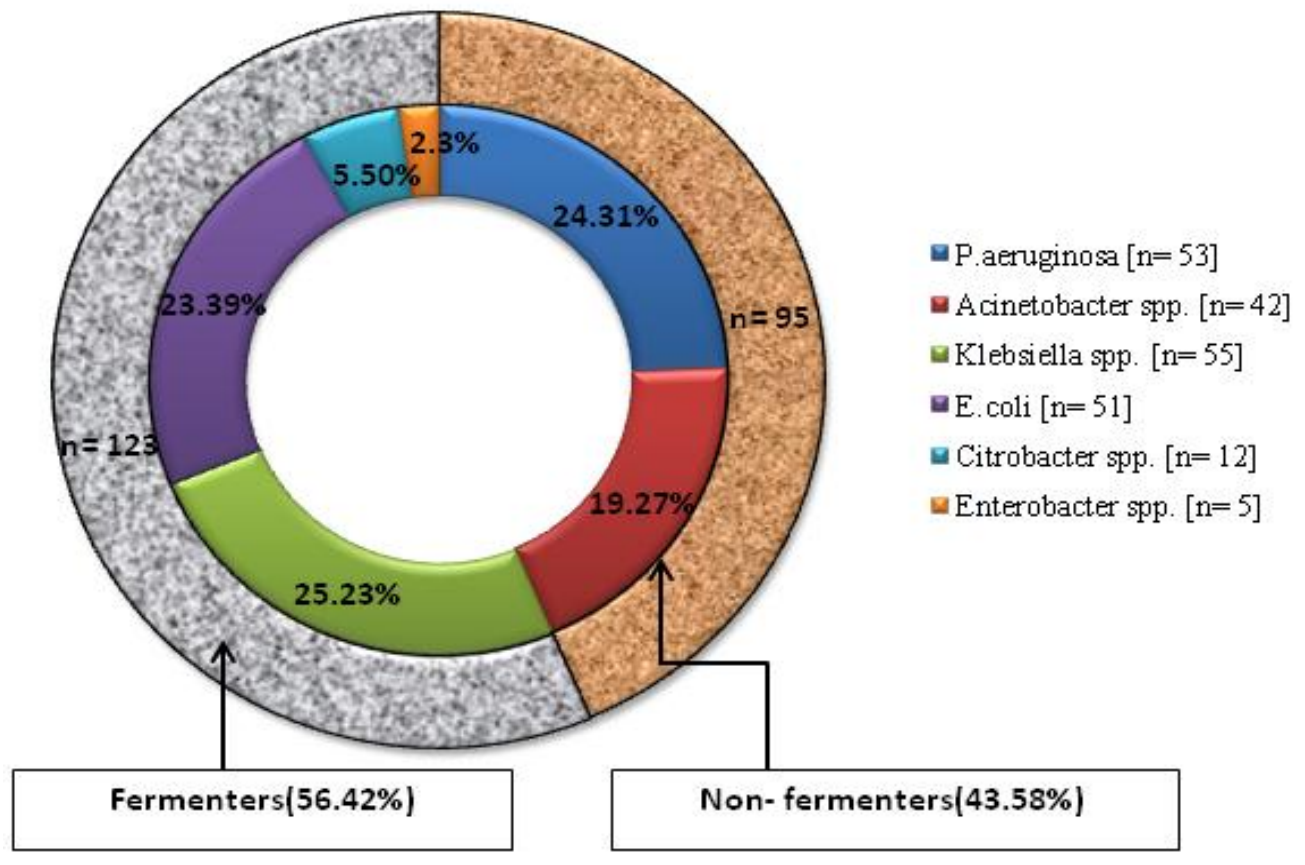

We found that Pseudomonas aeruginosa was highly prevalent in burn wounds. Klebsiella spp. was however most commonly associated with laparotomy wounds, closely followed by external fixator pin site wounds \& appendicular perforation surgical wounds. E.coli was also found to be associated with laparotomy wounds \& post operative appendicular perforation wounds. It was also noted that Acinetobacter spp. was mostly found in burn wounds. Citrobacter spp. \& Enterobacter spp., though meagre in number, were found mainly found in wounds from General Surgical wards. (chart-3)

Chart-3: Distribution of organisms in various types of infected wounds.

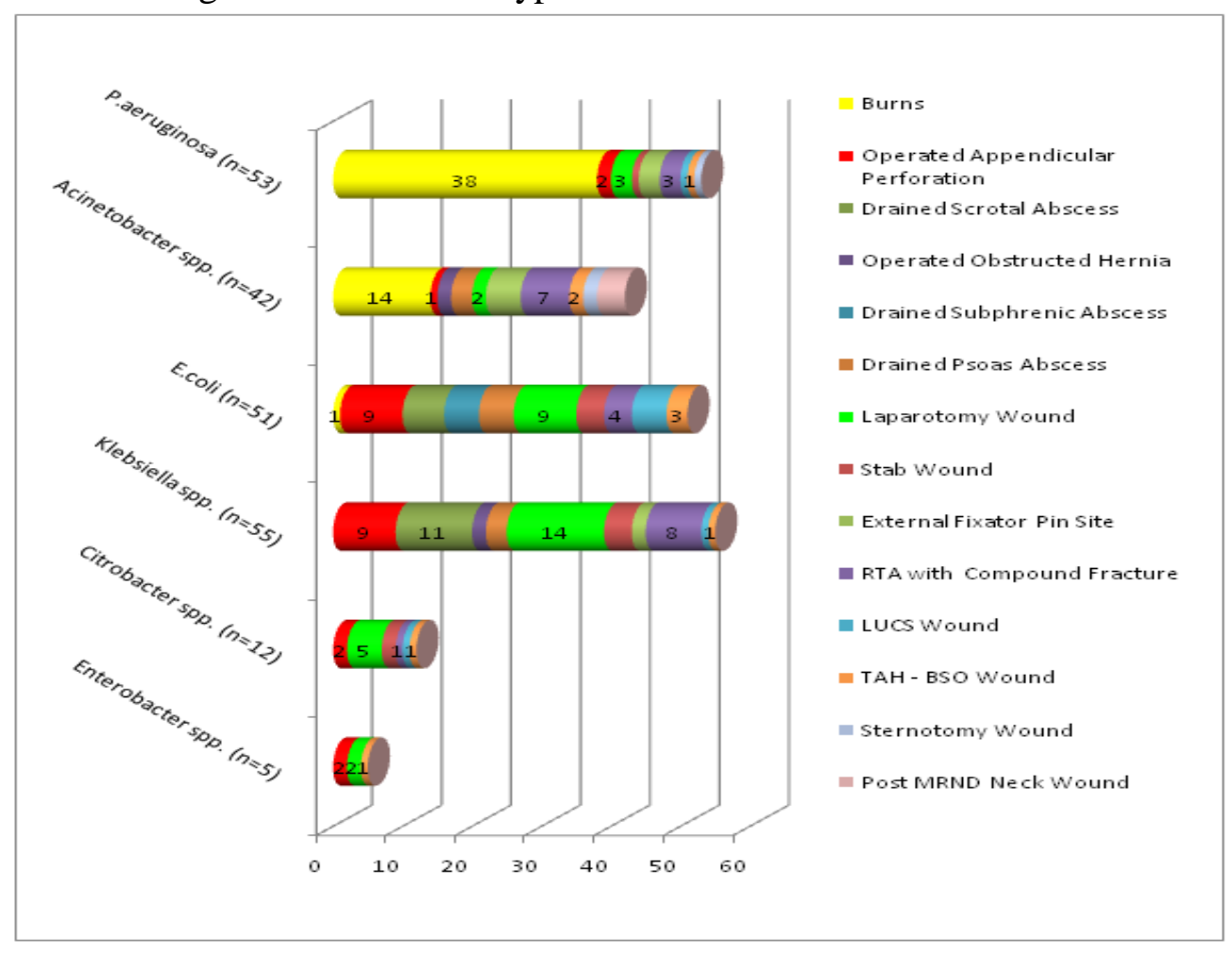


We found that among the Carbapenem resistant organisms, Pseudomonas aeruginosa was most prevalent $(60.65 \%)$, followed by Acinetobacter spp. $(39.35 \%)$.

Table-2: Sensitivity of the Non- fermenters by VITEK 2 compact

\begin{tabular}{|c|c|c|c|c|c|c|}
\hline & \multicolumn{3}{|c|}{$\begin{aligned} & \text { MIC interpretive criteria }(\mu \mathrm{g} / \mathrm{ml}) \\
& \text { MEROPENEM } \\
&\end{aligned}$} & \multicolumn{3}{|c|}{$\begin{array}{l}\text { MIC interpretive criteria }(\mu \mathrm{g} / \mathrm{ml}) \\
\text { IMIPENEM }\end{array}$} \\
\hline & $\mathbf{S}$ & $\mathbf{I}$ & $\mathbf{R}$ & $\mathbf{S}$ & $\mathbf{I}$ & $\mathbf{R}$ \\
\hline & $\leq 2$ & 4 & $\geq 8$ & $\leq 2$ & 4 & $\geq 8$ \\
\hline Acinetobacter spp. & $\begin{array}{c}16 \\
(40 \%)\end{array}$ & $\begin{array}{c}0 \\
(0 \%)\end{array}$ & $\begin{array}{c}24 \\
(60 \%) \\
\end{array}$ & $\begin{array}{c}16 \\
(40 \%)\end{array}$ & $\begin{array}{c}0 \\
(0 \%)\end{array}$ & $\begin{array}{c}24 \\
(60 \%)\end{array}$ \\
\hline Pseudomonas spp. & $\begin{array}{c}18 \\
(32.72 \%) \\
\end{array}$ & $\begin{array}{c}0 \\
(0 \%) \\
\end{array}$ & $\begin{array}{c}37 \\
(67.27 \%) \\
\end{array}$ & $\begin{array}{c}18 \\
(32.72 \%) \\
\end{array}$ & $\begin{array}{c}0 \\
(0 \%) \\
\end{array}$ & $\begin{array}{c}37 \\
(67.27 \%) \\
\end{array}$ \\
\hline
\end{tabular}

It was seen that among the MBL producers Pseudomonas aeruginosa $[\mathrm{n}=28]$ was most prevalent (66.66\%); followed by Acinetobacter spp.[n=14] (33.33\%).(chart-4)
Carbapenem sensitivity of the Non- fermenters by VITEK 2 compact system is as depicted in table 2 .

Chart-4: Prevalence of MBL producers by IMP -EDTA Combined Disc Diffusion Test.

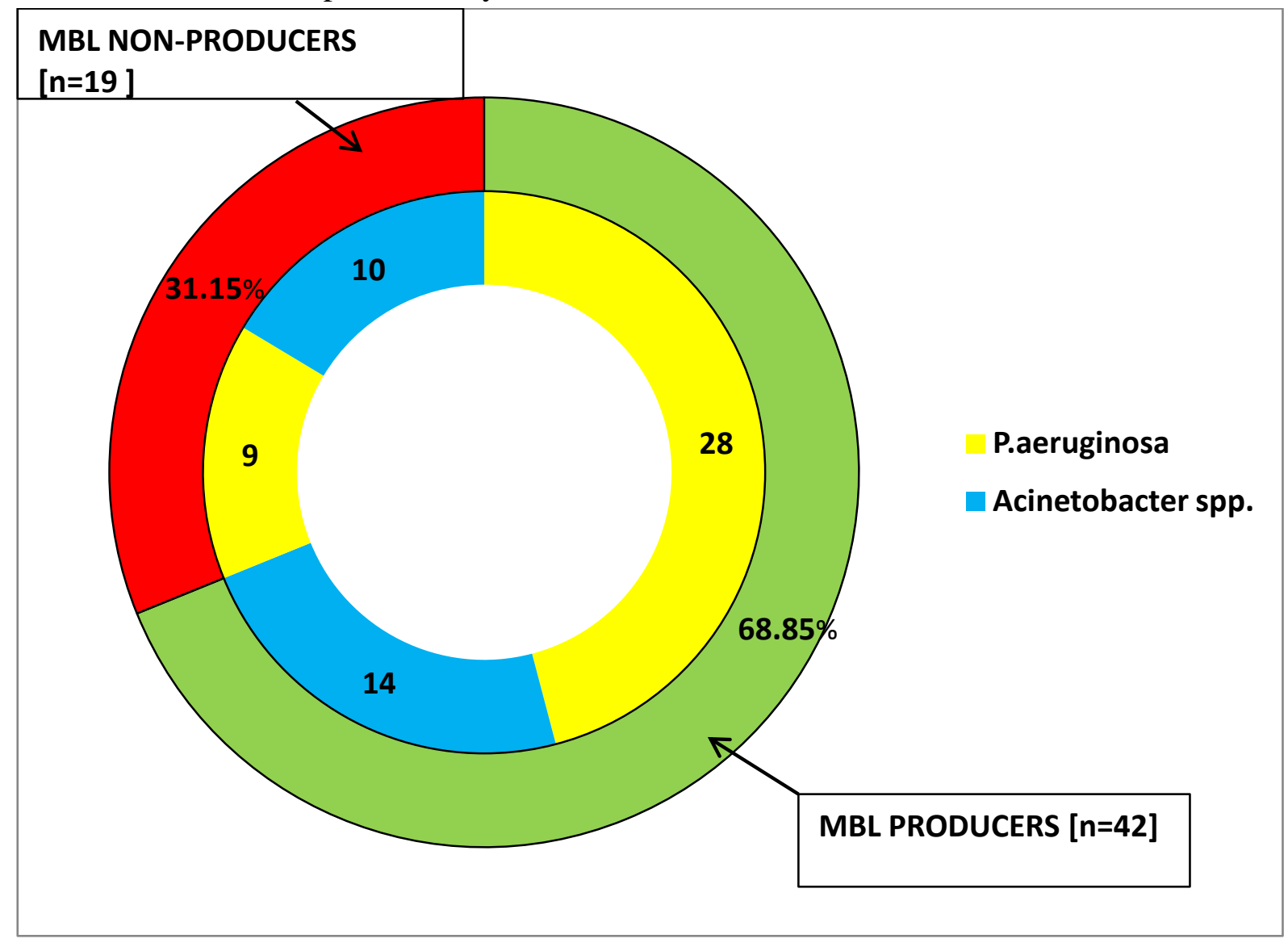

Finally, blavim gene was isolated from 7 samples (16.66\%)among the $42 \mathrm{MBL}$ producers. All of these 7 strains were Pseudomonas aeruginosa sensitive to Colistin. Also, the prevalence of metallo- $\beta$ - lactamase producing genes among non fermenting gram negative bacilli was ( 7 out of 95 ; ie $7.36 \%$ ). 
In this study, out of the 350 pus samples collected from wound infections, 218 were Gram negative bacilli $(62.29 \%)$. Similarly, predominance of Gram negative bacilli (85.05\%) in wound swabs has been shown in a study by Kemebradikumo Pondei et $\mathrm{al}^{3}$ conducted in Nigeria.

Regarding age distribution, in the current study, the maximum number of pus samples having Gram negative bacteria came from the age group 21-40years (40.83\%). This result is comparable with that of Rashid et $\mathrm{al}^{4}$ where the main age group affected was 21-40years (41.2\%).

According to the present study, among the 218 gram negative isolates, 55 were Klebsiella spp.; which was found to be the most common pathogen among the pus samples from wound infections. This was $25.23 \%$ of the total number of gram negative organisms. This result is very similar to a study conducted in Western Nigeria by Sule A et $\mathrm{al}^{5}$; where Klebsiella pneumoniae was observed as the most common pathogen $(25.3 \%)$ in wounds .

In the present study, we have found that of the total 55 samples received from infected burn wounds, 38 harboured Pseudomonas aeruginosa. Hence it was the most common (69.09\%) nonfermenter isolated from infected burn wounds. This result is supported by a study conducted by Mehta $\mathrm{M}$ et $\mathrm{al}^{6}$ at Government Medical College, Chandigarh ; where Pseudomonas aeruginosa was the most prevalent organism $(51.5 \%)$ in infected burn wounds.

In our study, we found that among the Carbapenem resistant non-fermenters, Pseudomonas aeruginosa was the most prevalent $(60.65 \%)$ organism. This corroborates with a study conducted in Turkey by Altoparlak $\mathrm{U}_{\text {et }} \mathrm{al}^{7}$; where also Pseudomonas aeruginosa was the most prevalent $(92.5 \%)$ strain among the carbapenem resistant organisms. Our study however does not corroborate with that conducted in Romania by Mihaela Ileana Ionescu et $\mathrm{al}^{8}$ where Acinetobacter spp. was the predominant $(80.62 \%)$ strain among the carbapenem resistant non-fermenters.
In our study, we have included Imp-EDTA combined disc method as a phenotypic test for differentiation of Metallo- $\beta$-lactamase producing non fermenters. We have found that $66.66 \%$ of Pseudomonas aeruginosa \& $33.33 \%$ of Acinetobacter spp. were Metallo- $\beta$-lactamase producers. Our result is similar with a study conducted in Tehran, Iran by Fatemeh Fallah et $\mathrm{al}^{9}$, where $57.9 \%$ of Pseudomonas aeruginosa were MBL producers by Imp-EDTA combined disc diffusion test.

In the present study, among the MBL producers,

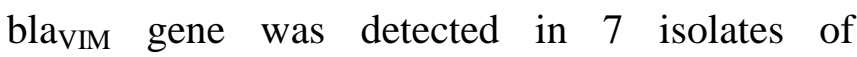
Pseudomonas aeruginosa (16.66\%). This result has similarity with a study conducted in Iran by Yousefi $\mathrm{S}$ et $\mathrm{al}^{10}$; where $17.3 \%$ of Pseudomonas aeruginosa isolates from Orumieh and Tabriz cities in northwest of Iran and $19.51 \%$ from Ahwaz in southwest of Iran were blavim gene positive.

\section{Conclusion}

To conclude, it was found that, development of Carbapenem resistance was quite prevalent (61 out of 350 . ie.- $17.43 \%$ ) among the organisms isolated from infected wounds in our hospital. Metallo- $\beta$-lactamase production by the nonfermenting bacteria led to the development of Carbapenem resistance in them. Presence of blavim gene is important in the development of Carbapenem resistance among the Metallo- $\beta$ lactamase producing Gram negative nonfermenters. The prevalence of metallo- $\beta$ lactamase producing genes among non fermenting gram negative bacilli was ( 7 out of 95 ; ie $7.36 \%$ )

\section{References}

1. Ambler RP.1980.The structure of $\beta$ lactamases. Philos Trans R Soc London Biol.289:321-331.

2. Clinical and Laboratory Standards Institute. Performance standards for antimicrobial disk susceptibility tests, twenty fourth Informational supplement (M100-S24), 2014. 
3. Pondei K, Fente BG, Oladapo O. Current Microbial Isolates from Wound Swabs, Their Culture and Sensitivity Pattern at the Niger Delta University Teaching Hospital, Okolobiri, Nigeria. Tropical Medicine and Health. 2013;41(2):49-53. doi:10.2149/tmh.2012-14.

4. Rashid, A., Chowdhury, A., Rahman, S.H.Z., Begum, S.A. and Muazzam, N. (2007) Infections by Pseudomonas aeruginosa and Antibiotic Resistance Pattern of the Isolates from Dhaka Medical College Hospital. Bangladesh Journal of Medical Microbiology, 1, 48-51.

5. Sule A, Thanni L, Sule-Odu O, Olusanya O. Bacterial pathogens associated with infected wounds in Ogun state university teaching hospital, Sagamu, Nigeria. Afr J Clin Exp Microbiol 2002;3:13-16.

6. Mehta M, Dutta P, Gupta V. Bacterial isolates from burn wound infections and their antibiograms: A eight-year study. Indian J Plast Surg 2007;40:25-8

7. Altoparlak U, Aktas F, Celebi D, Ozkurt $Z$, Akcay MN. Prevalence of metallo- $\beta$ lactamase among Pseudomonas aeruginosa and Acinetobacter

baumannii isolated from burn wounds and in vitro activities of antibiotic combinations against these isolates. Burns. 2005;31:707-10.

8. Ionescu MI, Neagoe DS, Chiorean C, Dumitras L, Rus A. Carbapenem Resistance in Non-Fermentative Bacterial Species and in Enterobacteriaceae Isolates from Hospitalized Patients in Different Health-Care Settings. Clujul Medical. 2014;87(4):235-241. doi:10.15386/cjmed282.
9. Fallah F, Borhan RS, Hashemi A. Detection of bla(IMP) and bla(VIM) metallo- $\beta$-lactamases genes among Pseudomonas aeruginosa strains. International Journal of Burns and Trauma. 2013;3(2):122-124.

10. Yousefi S, Farajnia S, Nahaei MR, Akhi MT, Ghotaslou R, Soroush MH, Naghili B, Jazani NH. Detection of metallo- $\beta$ lactamase-encoding genes among clinical isolates of Pseudomonas aeruginosa in northwest of Iran. Diagn Microbiol Infect Dis. 2010 Nov;68:322-5. 